Original Research Article

\title{
Monitoring of adverse drug reactions in medicine, paediatric and surgical departments of a tertiary care hospital: a prospective observational study
}

\author{
Sujatha Sowmyanarayan, Swati Banerjee*
}

Department of Pharmacology, East Point College of Medical Science and Research Centre, Bangalore, Karnataka, India

Received: 07 February 2018 Accepted: 07 March 2018

*Correspondence to:

Swati Banerjee,

Email: banerjee.swati84@ gmail.com

Copyright: () the author(s), publisher and licensee Medip Academy. This is an openaccess article distributed under the terms of the Creative Commons Attribution NonCommercial License, which permits unrestricted noncommercial use, distribution, and reproduction in any medium, provided the original work is properly cited.

\begin{abstract}
Background: the aim of the study was to monitor all adverse drug reactions in the departments of Medicine, Paediatrics and Surgery in a Tertiary Care Hospital. Methods: It was a prospective study undertaken in a 300 bedded tertiary care hospital. Patients presenting with adverse drug reactions in Medicine, Paediatrics and Surgery Departments were studied. Causality and severity of the adverse drug reactions were analysed Other parameters such as age wise and gender wise distribution of the ADRs, types of ADRs and drugs causing ADRs were studied. Results: There were 33 cases of ADRs were enrolled for the study in the duration of Sept. 2016 to Aug. 2017. Female preponderance was seen. The largest number of ADRs were seen in the age group of 21-30 years (30.3\%). The most common ADR was skin rash $(30.3 \%)$ followed by periorbital edema $(12 \%)$. There were two SAEs namely Anaphylaxis and Steven Johnson syndrome. The most offending class of drug was antibiotics $(30.3 \%)$ followed by intravenous fluids (12.1\%).

Conclusions: The maximum number of cases were reported from the Medicine Department which was $11(33.33 \%)$. The highest number of ADRs fell in the probable category $(63.6 \%)$. The number of cases of mild and moderate severity were equal (42.4\%). The knowledge of these adverse drug reactions is necessary while prescribing drugs to patients as patient safety is absolutely essential. Also the healthcare provided by the institution will improve. This data has been collected with a view to establish an ADR monitoring centre at our hospital.
\end{abstract}

Keywords: Adverse drug reaction, Causality, Drugs causing, Severity

\section{INTRODUCTION}

Drugs are meant to relieve suffering but sometimes they themselves can cause adverse drug reactions ranging from minor inconvenience to serious organ dysfunction or even death. Their awareness to the medical world, public and official bodies was highlighted mainly after the Thalidomide disaster in $1961 .^{1}$ The WHO defines ADR as "Any reaction which is noxious and unintended, and which occurs in man due to use of a drug for the prevention, treatment or diagnosis of disease or for the modification of physiological function". ${ }^{2}$
WHO defines Pharmacovigilance as "The science and activities which are related to the detection, assessment, understanding and the prevention of adverse effects or any other drug related problems". ${ }^{3}$ ADRs are a common cause of morbidity and place a substantial burden on limited healthcare resources. ${ }^{4}$ Adverse drug reactions constitute a significant economic burden for hospitals. Hospital based adverse drug reaction monitoring and reporting programmes aim to identify and quantify the risks associated with the use of drugs provided in a hospital setting. ${ }^{4}$ A study conducted at four hospitals in South Africa showed that $2.9 \%$ and $16 \%$ of the mortality were 
due to ADRs and ADR related complications respectively. ${ }^{5}$

Studies have found the overall incidence of adverse drug reactions in skin in developed countries as $1-3 \%$ and in the developing countries it is higher between 2-5\%.,6 5-10\% of hospital admissions are due to drug related problems, in which $50 \%$ are avoidable. ${ }^{7}$ ADR reporting is crucial because two independent studies in India have concluded that some patient groups are at a particular risk of developing ADRs, for example infants, those using cardiovascular drugs and patients receiving four or more types of medication. 8,9

Adverse reactions are recognized hazards of drug therapy. Early detection, evaluation and monitoring of Adverse drug reactions are essential to reduce harm to patients and thus improve public health. With the increase in the production of various pharmaceutical products, newer drugs are being introduced every year. ${ }^{10}$ Hence it has become essential to monitor the effects and adverse drug reactions pertaining to these drugs.

The present study was undertaken in order to study the adverse drug reactions in the departments of Medicine, Paediatrics and Surgery including ENT and Gynaecology as a part of the Pharmacovigilance study of East Point Medical College and Hospital. The aim was to develop an efficient ADR monitoring centre at the Hospital.

\section{Benefits of ADR monitoring ${ }^{11,12}$}

An ADR monitoring and reporting programme can furnish following benefits:

- It caters information about quality and safety of pharmaceutical products.

- It initiates risk-management plans.

- It prevents the predictable adverse effects and helps in measuring ADR incidence.

- It instructs health care team, patients, pharmacists and nurses about adverse drug effects and creates awareness regarding ADRs.

\section{Aims and objectives}

- To study the adverse drug reactions with regard to their causality, severity, drugs causing the ADRs, clinical presentation of the ADRs.

- $\quad$ To study the gender wise and age wise distribution of the ADRs and the duration of exposure.

\section{METHODS}

This was a prospective, observational, descriptive study carried out at East Point Medical College and Hospital. The hospital is a 300 bedded tertiary care hospital. The study was carried out for a period of one year. All the patients who reported in the departments of Medicine, Surgery, Gynaecology of the hospital with suspected ADR during the study period were included in the study.

\section{Table 1: WHO UMC causality assessment Scale.}

\begin{tabular}{|c|c|}
\hline Causality term & Assessment criteria \\
\hline Certain & $\begin{array}{l}\text { - } \\
\text { Event or laboratory test abnormality, with plausible time relationship to drug intake } \\
\text { - } \\
\text { - } \\
\text { Response to withdrawal plausible (pharmacologically, pathologically) } \\
\text { medical disorder or a recognized pharmacologic phenomenon) } \\
\text { - } \\
\text { Rechallenge satisfactory, if necessary }\end{array}$ \\
\hline Probable/Likely & $\begin{array}{l}\text { Event or laboratory test abnormality, with reasonable time relationship to drug intake } \\
\text { - } \\
\text { - } \\
\text { Rnlikely to be attributed to disease or other drugs } \\
\text { Rechonse to withdrawal clinically reasonable } \\
\text { Rechallenge not required }\end{array}$ \\
\hline Possible & $\begin{array}{l}\text { - } \\
\text { - } \\
\text { - }\end{array}$ \\
\hline Unlikely & $\begin{array}{l}\text { - Event or laboratory test abnormality with a time relationship to drug intake that makes a } \\
\text { relationship improbable (but not impossible) }\end{array}$ \\
\hline $\begin{array}{l}\text { Conditional/ } \\
\text { Unclassified }\end{array}$ & $\begin{array}{l}\text { Event or laboratory test abnormality } \\
\text { - } \\
\text { More data for proper assessment needed or } \\
\text { Additional data under examination }\end{array}$ \\
\hline $\begin{array}{l}\text { Unassessable/ } \\
\text { Unclassifiable }\end{array}$ & $\begin{array}{l}\text { - } \\
\text { - } \\
\text { - }\end{array}$ \\
\hline
\end{tabular}


The diagnosis of the adverse drug reaction was based on the history of drug exposure and clinical findings and was done by the consultant Physician or Surgeon or Gynaecologist depending on the respective department. The parameters were recorded on an ADR monitoring form which included Demographic characteristics of the patient, type of ADR, drug causing ADR, duration of exposure, causality, severity, treatment for the ADR. Causality was assessed based on the WHO Causality Assessment Scale and severity was assessed based on the Hartwig and Siegel Scale.

The causality assessment of the adverse drug reactions was done using this scale. ${ }^{13}$

\section{Severity assessment by the modified hartwig and Siegel Severity Assessment Scale ${ }^{14}$}

Severity of the adverse drug reactions was assessed using the Modified Hartwig and Siegel Severity Assessment Scale. The severity is broadly categorized into "mild", "moderate" and "severe" for each ADR. The suspected ADR is mild when "an ADR occurs but requires no change in treatment with the suspected drug. or the ADR requires that treatment with suspected drug be held, discontinued, or otherwise changed. No antidote or other treatment was required. The suspected ADR is "moderate" when the ADR requires treatment with the suspected drug be held, discontinued or otherwise changed and or an antidote or other treatment was required. No increase in length of stay (LOS) or any level 3 ADR that increases LOS by atleast one day or the ADR was the reason for the admission.

\section{RESULTS}

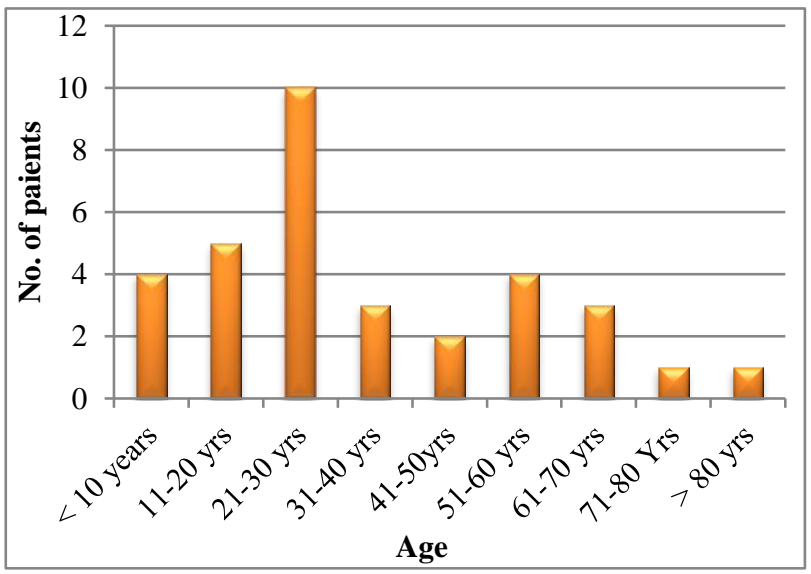

Figure 1: Age wise distribution of patients.

In the present study, there were various types of adverse drug reactions which were due to various drugs. The results were calculated in the form of percentages. A total of 33 adverse drug reactions were reported during the period of the study. The maximum number of cases of adverse drug reactions were seen in the age group of 21 30 years $(30.3 \%)$ followed by $11-20$ years $(15.1 \%)$ followed by $51-60$ years $(12.1 \%)$ and less than 10 years
(12.1\%). There were only two cases seen above the age of seventy years $(6.1 \%)$.

The number of adverse drug reactions were more in females than in males. Out of thirty-three cases, 11 cases (33.33\%) of ADRs were seen in males and 22 cases $(66.66 \%)$ were seen in females. There was a female preponderance (Figure 2).

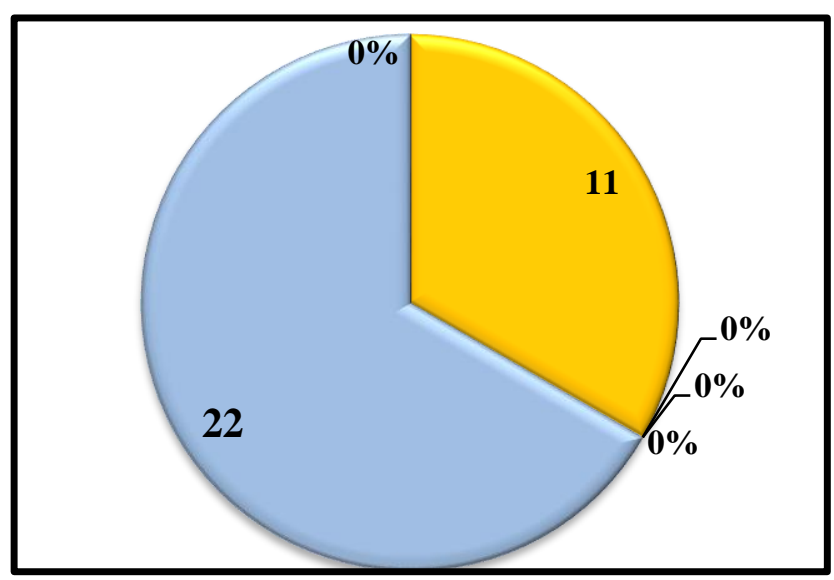

Figure 2: Gender wise distribution of ADRs.

The maximum number of ADRs were reported from the department of Medicine (33.3\%) followed by Surgery $(27.3 \%)$ and followed by Paediatrics (18.2\%). Few cases were reported from Gynaecology (12.1\%), ENT (6.1\%) and Ophthalmology (3\%) departments also (Figure 3).

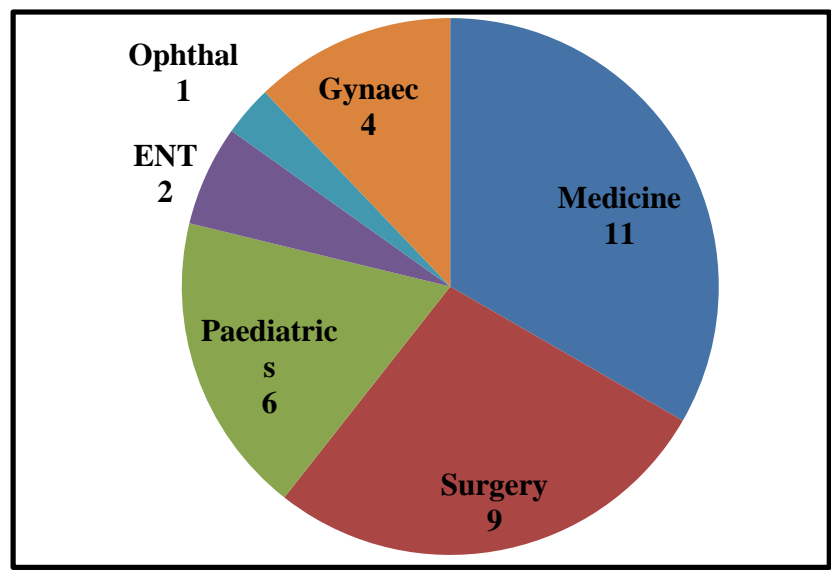

Figure 3: Department wise distribution of ADRs.

Drug rash was the commonest clinical presentation seen in 9 cases $(27.2 \%)$. The other cases seen were Steven Johnson syndrome $1(3 \%)$, Anaphylaxis $1(3 \%)$, Oculogyric crisis $1(3 \%)$, fever with chills $2(6 \%)$, pruritis $2(6 \%)$, rash with pruritis $2(6 \%)$, periorbital edema $4(12 \%)$, FDE2 (6\%), local swellings $2(6 \%)$, oesophagitis $2(6 \%)$, chills $1(3 \%)$, vomiting $1(3 \%)$ and edema in skin $1(3 \%)$, swelling of lips $1(3 \%)$ and swelling of ear lobe $1(3 \%)$ (Figure 4$)$.

Antibiotics caused the largest number of ADRs (30.3\%), followed by intravenous fluids $(12.1 \%)$, analgesics $(9.1 \%)$, 
vaccines $(9.1 \%)$, anaesthetics $(6.1 \%)$, Vitamin (3\%), Iron (3\%) anti-psychotic (3\%), Phenytoin Sodium (3\%) and Metformin (3\%), Hydroxychloroquine (3\%), Metronidazole (3\%), Acetylcysteine (3\%), Atorvastatin (3\%), Anti-snake venom (3\%), Ondansetron (3\%) (Figure $5)$.

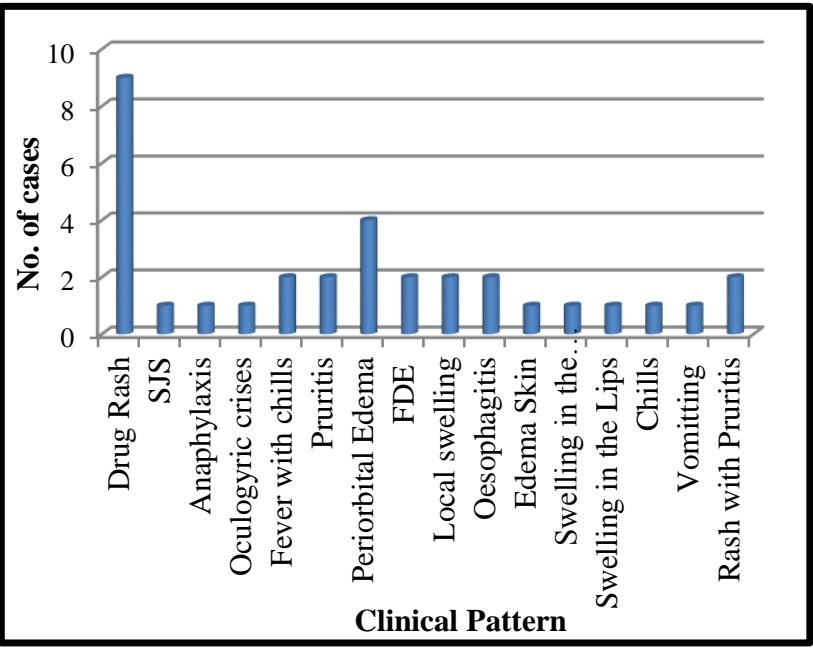

Figure 4: Clinical pattern of ADRs.

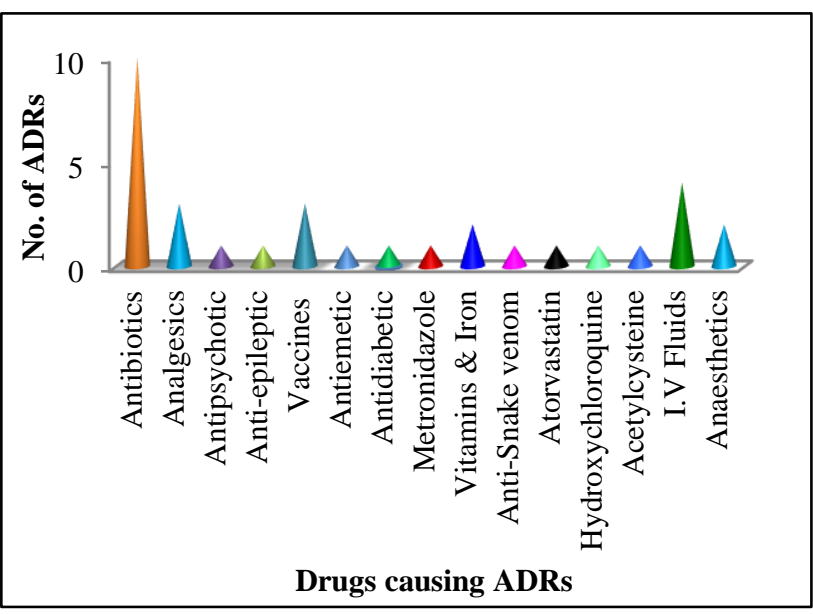

Figure 5: Drugs causing ADRs.

Among the ADRs reported, the highest number of ADRs fell in the Probable (63.6\%) category as regards causality, followed by Certain (21.2\%) and then the remaining ADRs were classified as Possible (15.1\%). The Causality was assessed using the WHO-UMC Causality Assessment Scale (Table 2).

Table 2: Causality assessment.

\begin{tabular}{|lll|}
\hline WHO category & Number of patients & Percentage \\
\hline Certain & 7 & 21.2 \\
\hline Probable & 21 & 63.6 \\
\hline Possible & 5 & 15.1 \\
\hline
\end{tabular}

\section{Severity}

The severity of the ADRs was classified according to the Hartwig and Siegel Severity Scale. An equal number of ADRs could be classified as Moderate (42.4\%) and Mild $(42.4 \%)$. Severe cases accounted for a lesser number (12.1\%) (Table 3).

Table 3: Severity assessment.

\begin{tabular}{|lll|}
\hline Severity & Number & Percentage \\
\hline Mild & 14 & 42.4 \\
\hline Moderate & 14 & 42.4 \\
\hline Severe & 5 & 12.1 \\
\hline
\end{tabular}

\section{DISCUSSION}

The maximum number of cases of adverse drug reactions were seen in the age group of 21-30 years (30.3\%) followed by $11-20$ years (15.1\%) followed by 51-60 years $(12.1 \%)$ and less than 10 years $(12.1 \%)$. There were only two cases seen above the age of seventy years $(6.1 \%)$. In a study conducted in Brazil the maximum number of ADRs were seen in the adult age group as compared to children. ${ }^{2}$ The findings in another study conducted in central India also matches with our study in that cutaneous adverse drug reactions were maximum in the 21-30 years age group. ${ }^{13}$

Even in the study conducted on adverse effects of antimicrobials the highest number of ADRs were found in the adult age group (63.1\%). There was a female preponderance. ${ }^{14}$ This matches with other studies carried out in South India. ${ }^{15,16}$

The maximum number of cases were reported from the department of Medicine (33.33\%) whereas from Surgery (27.3\%), and ENT (6.1\%). This may be due to under reporting of cases and or lack of awareness that the ADRs have to be reported. The most common ADR was skin rash. This is in accordance with another study conducted in central India in 2014. ${ }^{13}$ There were two Serious adverse events, one being Steven Johnson Syndrome due to Phenytoin Sodium and Linezolid and the other Anaphylaxis due to N-Acetylcysteine. Oculogyric crisis caused by Ondansetron is a rare adverse effect and requires a special mention. In this study antibiotics were the group contributing to maximum number of ADRs (30.3\%). This finding is similar to other studies conducted. ${ }^{17,18}$ Among the antibiotics Intravenous Ceftriaxone was the most common offending agent. There were reactions caused by intravenous fluids such as Normal saline. Another special mention needs to be made about a skin rash occurring due to vitamin B complex capsules given orally. Most of the adverse drug reactions fell in the probable (63.6\%) category with regard to Causality assessment according to the WHO-UMC Causality Assessment criteria as was seen in the study carried out in Thrissur on adverse drug reactions to psychotropic drugs and the study on antimicrobials. ${ }^{14,19}$ The reason for this is that rechallenge is not ethical. The majority of the ADRs were either mild or 
moderate in severity $(42.4 \%)$ each category while severe reactions were very few (12.1\%). The moderate ADRs had to be treated appropriately.

\section{CONCLUSION}

All physicians need to be aware of that ADRs may occur with as simple a drug as a vitamin tablet and hence exercise precaution while prescribing drugs. ADRs that occurred in this hospital are comparable to other studies, with differences in some aspects. Antibiotics were the most common group of drug causing ADRs and this included Ceftriaxone and Linezolid. Intravenous fluids such as Normal saline and Dextrose can also lead to ADRs. Results of our study emphasize the need of reporting ADRs in a hospital in order to assess the benefit-risk ratio of drugs and improve health care.

Funding: No funding sources Conflict of interest: None declared

Ethical approval: The study was approved by the Institutional Ethics Committee

\section{REFERENCES}

1. Amrinder R, Kaur I, Singh J, Kaur T. Monitoring of cutaneous adverse drug reactions in a Tertiary Care Hospital J Pharmacovigilance. 2016;4:207.

2. Amin MN, Khan TM, Dewan SMR, Islam MS, Moghal MR, Ming LC. Cross-sectional study exploring barriers to adverse drug reactions reporting in Community pharmacy settings in Dhaka, Bangladesh BMJ Open. 2016;6(8).

3. Pharmacovigilance. World Health Organisation. 2016 Available at: http://www.who.int/medicines/areas/quality_safety/sa fety_efficacy/pharmacovigi/en /.

4. Lobo MG, Pinheiro SM, Castro JG, Momente VG, Pranchevicius MC. Adverse Drug Reaction Monitoring: Support for Pharmacovigilance at a tertiary care hospital in Northern Brazil BMC Pharmacol. Toxicol. 2013;14:5.

5. Sharma R, Dogra D, Dogra N. A study of cutaneous adverse drug reactions in a tertiary centre in Jammu, India. Indian Dermatol Online J. 2015;6:168-71.

6. Prajapati K, Desai M, Shah S, Panchal J, Kapadia J, Dikshit R. An analysis of serious adverse drug reactions at a tertiary care teaching hospital. Perspectives in Clinical Research. 2016;7(4):181-6.

7. Nivya K, Sai Kiran VS, Ragoo N, Jayaprakash B, Sonal SM. Systematic review on drug related hospital admissions. Saudi Pharm Journal. 2015;23(1):1-8. PubMed.

8. Kurian J, Mathew J, Sowjanya K. Adverse Drug Reactions in hospitalized paediatric patients: a prospective observational study. Indian J Paediatr. 2016;83:414-9.
9. Palaniappan $\mathrm{M}$, Selvarajan $\mathrm{S}$, George $\mathrm{M}$, Subramaniyan G, Dkhar SA, Pillai AA, et al. Pattern of adverse drug reactions reported with cardiovascular drugs in a tertiary care teaching hospital. Journal of clinical and diagnostic research: JCDR. 2015 Nov;9(11):FC01.

10. Shamna M, Dilip C, Ajmal M, Linu Mohan P, Shinu C, Jafer CP, Mohammed YA. Prospective study on Adverse Drug Reactions of antibiotics in a tertiary care hospital. Saudi Pharm J. 2014;22(4):303-8.

11. Moore N. The role of the Clinical Pharmacologist in the management of ADRs. Drugs Saf. 2001;24(1):1-7.

12. Murphy BM, Frigo LC. Development, implementation, and results of a successful multidisciplinary adverse drug reaction reporting program in a university teaching hospital. Hospital pharmacy. 1993 Dec;28(12):1199-204.

13. Verma R, Tiwari S, Gupta CM, Verma N. Cutaneous adverse drug reactions- Astudy of clinical patterns, causality, severity and preventability Journal of Dental and Medical Sciences. 2014;13:102-9.

14. Tandon VR, Sharma S, Khajuria V, Mahajan V, Gillani Z. Adverse drug reactions profile of antimicrobials: A 3-year experience, from a tertiary care teaching hospital of India. Indian Journal of Medical Microbiology. 2015 Jul 1;33(3):393.

15. Lamani VL, Ratnakar JS, Kotnatot BC, Bhusan. A Study of cutaneous adverse drug reactions in a tertiary care teaching hospital. Int $\mathbf{J}$ of Basic and App Med Sci. 2015;5:71-4.

16. Pudukadan D, Thappa DM. Adverse cutaneous drug reactions, clinical pattern and causative agents in a tertiary care centre in South India. Indian Journal of Dermatology, Venereology and Leprology. 2004;70:20-4.

17. Ramakrishnaiah H, Krishnaiah V, Pundarikaksha P, Ramakrishna V. A prospective study on adverse drug reactions in outpatients and inpatients of Medicine department in a tertiary care hospital Int.J of Basic and Clin. Pharmacol. 2015;4(3):515-21.

18. Saha A, Das NK, Hazra A, Gharami RC, Chowdhary SN, Datta PK .Cutaneous adverse drug reaction profile in a tertiary care outpatient setting in Eastern India. Indian J Pharmacol. 2012;44:792-7.

19. Harichandran DT, Viswanathan MT, Gangadhar R. Adverse Drug Reactions among hospitalized patients in Psychiatry Department in a tertiary care hospital. J Health Res Rev. 2016;3:77-80.

Cite this article as: Sowmyanarayan S, Banerjee S. Monitoring of adverse drug reactions in medicine, paediatric and surgical departments of a tertiary care hospital: a prospective observational study. Int J Basic Clin Pharmacol 2018;7:778-82. 